Rev. Adv. Mater. Sci. 56 (2018) 124-138

\title{
SYNTHESIS AND PROPERTIES OF ZIRCONIA-GRAPHENE COMPOSITE CERAMICS: A BRIEF REVIEW
}

\author{
A.G. Glukharev ${ }^{1,2}$ and V.G. Konakov ${ }^{1,2}$ \\ 'Institute for Problems of Mechanical Engineering RAS, Bolshoy 61 VO, St. Petersburg, 199178, Russia \\ ${ }^{2}$ Saint Petersburg State University, Universitetskya nab. 7/9, St Petersburg, 199034, Russia
}

Received: April 30, 2018

\begin{abstract}
The paper summarizes current data on ceramic zirconia-graphene composites. Basic types of graphene-containing additives and the main approaches for composite synthesis are considered. The effect of the additive type and synthesis procedure on the composite structure, mechanical (microhardness and crack resistivity) and electrical (conductivity at room and at elevated temperature) properties of the material is discussed.
\end{abstract}

\section{INTRODUCTION}

Over the past decade, graphene has attracted increasing attention of investigators working in the different field of science and technology; this interest resulted in a growing number of papers and patents dealing with graphene and graphene-based materials. Obviously, the above interest is due to the fact that graphene ( $\mathrm{Gr}$ ) possesses a set of unique properties: high specific surface area $\left(2630 \mathrm{~m}^{2} / \mathrm{g}\right.$, [1]), high electron mobility (2 $\left.105 \mathrm{~cm}^{2} \mathrm{~V}^{-1} \mathrm{~S}^{-1},[1-3]\right)$, high Young modulus value ( $\approx 1 \mathrm{TPa},[4])$, and good thermal conductivity $(\approx 500 \mathrm{~W} / \mathrm{mK}$, [5]). Regarding for these properties, graphene itself and graphenebased materials are widely used for the development of functional materials with a tailored structure and high mechanical properties. Note that the aim of such studies is not limited by theoretical in- terest only, specific applications in modern technology are also widely discussed.

Analysis of recent literature indicated the significant progress in the development of "coarsegrained metal graphene" and "ultrafine-grained metal graphene" composites [6,7-10], approaches for such materials modeling could be found in, e.g., [11]; "polymer matrix-graphene" [1,12-15]. As for ceramic materials, the effect of $\mathrm{Gr}$ addition to a non-oxide ceramic matrix $\left(\mathrm{SiC}, \mathrm{Si}_{3} \mathrm{~N}_{4}\right.$, BN, etc., see, e.g. [1618]) on the material structure, their electrical conductivity and mechanical properties is studied well enough. At that, the same information for the case of oxide ceramics matrix and, in particular, $\mathrm{ZrO}_{2}$ is rather limited: the effect of carbon-base additives on physical, chemical, and mechanical properties of the sintered materials in unclear. Zirconia-based composites reinforced by carbon nanotubes (CNT)

Corresponding author:A.G. Glukharev, e-mail: gluharev1@gmail.com

(C) 2018 Advanced Study Center Co. Ltd. 
were widely studied over the past decade [19-25], an ambiguous effect of such additive has been shown. From one hand, carbon nanotubes addition increases some mechanical characteristics of the material (e.g., crack resistance); however, the strength of the materials is usually decreased. The onset of electron conductivity was reported for zirconia-CNT composites at the significant amount of nanotubes (1-6 wt. \%) [26-28]; the authors of [27] consider this effect as following from the problem of uniform introduction of CNT in the ceramics structure, CNT agglomeration, as well as by partial CNT destruction at thermal treatment.

Since some of the above problems could be successfully solved in the case of 2D materials, the attempts to use graphene as a carbon additive to zirconia matrix were carried out, most of these works focuses on the tetragonal $\mathrm{ZrO}_{2}$ due to the fact that this material is widely used in dentistry for dental crowns and implants production $[29,30]$. However, the information reported in the available literature is rather incomplete and contradictory; thus, the effect of graphene addition to zirconia matrix on the composite properties is still unclear. Generally, this is due to the well-known non-stability of the graphene monolayer causing the wide variety of Gr-containing additions which are more stable; in turn, approaches for their introduction into the ceramic matrix, composite compacting and heat treatment differ significantly. As a result, characteristics of the composites with the same composition as well as the conclusions of their nature and properties could be quite inconsistent.

Summarizing the above discussion, one can conclude that the task of the intentional synthesis of $\mathrm{ZrO}_{2}-\mathrm{Gr}$ composites with necessary properties requires the systematic analysis and critical review of the synthesis approaches. The aim of the present work is to summarize the available data on the effect of type and amount of Gr-containing additives along with the techniques of their introduction into zirconia matrix on the structure, electric conductivity and mechanical properties of $\mathrm{ZrO}_{2}-\mathrm{Gr}$ composites.

\section{SYNTHESIS APPROACHES FOR ZIRCONIA-GRAPHENE COMPOSITES MANUFACTURING}

The development of synthesis procedures providing the production of $\mathrm{ZrO}_{2}$-Gr composites with the preset properties requires the analysis of physical and chemical properties of the composite components and their advantages and drawbacks.

\subsection{Brief characterization of physical, chemical, and mechanical properties of zirconia and stabilized zirconia}

$\mathrm{ZrO}_{2}$ at $1 \mathrm{~atm}$ exists in the following three crystalline modifications [31]: monoclinic $\left(m-\mathrm{ZrO}_{2}, \rho=5.83\right.$ $\mathrm{g} / \mathrm{cm}^{3}$ ) thermally stable up to $1170^{\circ} \mathrm{C}$, monoclinic modification is usually used as a raw material for refractories production [32]. The phase transition into the tetragonal modification $\left(t-\mathrm{ZrO}_{2}, \rho=6,1 \mathrm{~g} / \mathrm{cm}^{3}\right)$ occurs at temperatures exceeding $1170{ }^{\circ} \mathrm{C}$, this modifications at cooling stays in the metastable state. At higher temperatures $\left(\geq 2370^{\circ} \mathrm{C}\right)$ tetragonal modification transfers into the cubic one $\left(c-\mathrm{ZrO}_{2}\right.$, $\rho=6.09 \mathrm{~g} / \mathrm{cm}^{3}$ ) that possesses the most symmetric crystalline structure, however, $c-\mathrm{ZrO}_{2}$ is unstable at low temperatures.

Due to the above mentioned instability of $t$-and c-zirconia at low temperatures, $\mathrm{ZrO}_{2}$-based solid solutions with a number of oxide additives (alkaliearth and rare-earth metal oxides) and are widely produced, these materials are known as "Ceramic steels". This name was used for the first time in [33], the authors manifested the excellent mechanical properties of the ceramics based on stabilized zirconia. So, the name "Ceramic steel" was chosen to highlight the similarity of such ceramics with steel since the thermal expansion coefficient and shear modulus of the materials were shown to be quite close. Obviously, the melting temperature of the $\mathrm{ZrO}_{2}$-based ceramics was significantly higher: 2680 ${ }^{\circ} \mathrm{C}$ for ceramics against $1420-1450{ }^{\circ} \mathrm{C}$ typical for steel. Note that mechanical and electrical properties of the stabilized zirconia depend on the type and amount of doping oxide, the materials are generally subdivided into:

- CSZ (Cubic Stabilized Zirconia): cubic solid solution based on $\mathrm{ZrO}_{2}$; the content of $\mathrm{MgO}$ or $\mathrm{CaO}$ to synthesize this material should be more than 12-15 mol.\%, while the amount of $\mathrm{Y}_{2} \mathrm{O}_{3}$ is usually $\geq 8$ mol.\%. CSZ possesses relatively low strength properties: bending strength $\sigma_{\text {bend }}$ is usually below 250 $\mathrm{MPa}$ and crack resistivity $K_{1 \mathrm{c}}$ is less than $3 \mathrm{MPa}$ $\mathrm{m}^{1 / 2}$. These materials are usually used as refractories, in addition, they are used in solid electrolytes technologies [34-36];

- ZTC (Zirconia Toughened Ceramic): dispersed $t$ $\mathrm{ZrO}_{2}$ particles are distributed in the ceramic matrix, they are stabilized by compressive stresses. $\mathrm{Al}_{2} \mathrm{O}_{3}$ $\mathrm{ZrO}_{2}$ (ZTA: Zirconia Toughened Alumina) composites are most important for technical applications, primarily, they are used as tool materials. Optimal 


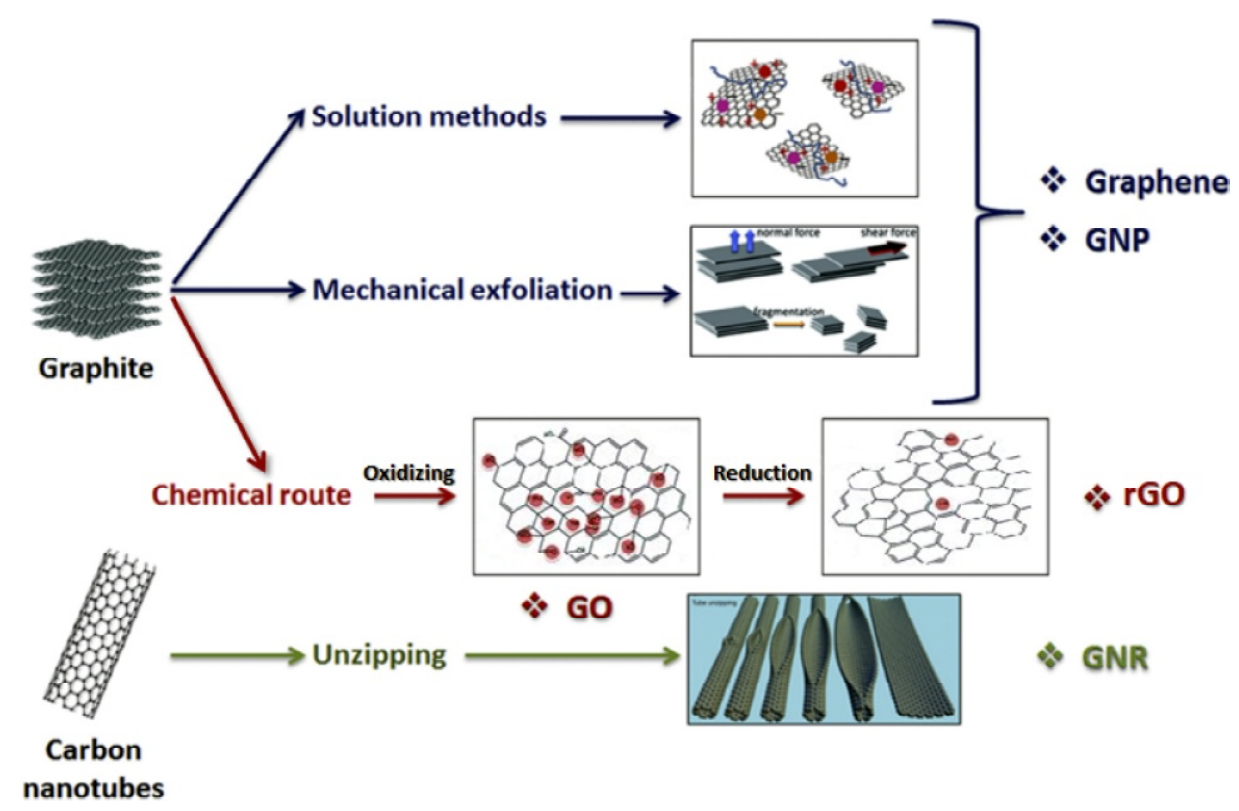

Fig. 1. The common scheme of graphene additives synthesis, summary of the approaches reported in [45-47].

mechanical characteristics here are usually achieved at $\mathrm{ZrO}_{2}$ content $\sim 15$ vol. $\%$, the values of $\sigma_{\text {bend }}$ up to $1000 \mathrm{MPa}$ and $K_{1 \mathrm{c}}$ up to $7 \mathrm{MPa} \mathrm{m}^{1 / 2}$ could be obtained [37].

- PSZ (Partially Stabilized Zirconia): these composites are formed as a result of $\mathrm{Mg}, \mathrm{Ca}$, and $\mathrm{Y}$ oxides addition into zirconia matrix. At that, rather coarse cubic zirconia grains with the average linear dimensions $\sim 60 \mu \mathrm{m}$ are formed at high temperature baling in the region of cubic phase homogeneity, while tetragonal particles coherently linked with the cubic phase appear in the double-phase region. The typical size of $t-\mathrm{ZrO}_{2}$ particles in $\mathrm{ZrO}_{2}-\mathrm{MgO}(\mathrm{CaO})$ systems should be less than $0.25 \mu \mathrm{m}$ since the coherence is broken in the case of $t-\mathrm{ZrO}_{2}$ particles coarsening; as a result, their reinforcing ability is drastically decreased. The content of $t-\mathrm{ZrO}_{2}$ phase is usually $\sim 40$ vol.\%. PSZ materials are widely used in mechanical engineering due to their high mechanical properties ( $\sigma_{\text {bend }}$ up to $1500 \mathrm{MPa}$ and $K_{1 \mathrm{c}}$ up to $\left.10 \mathrm{MPa} \mathrm{m}^{1 / 2}\right)[38,39]$.

- TZP (Tetragonal Zirconia Polycrystals): this material can be obtained in $\mathrm{ZrO}_{2}-\mathrm{Y}_{2} \mathrm{O}_{3}$ or $\mathrm{ZrO}_{2}-\mathrm{CeO}_{2}$ systems; it contains tetragonal grains only. Material baking here is usually carried out in the region of $t$-phase homogeneity, it is followed by quenching. The energy dissipation at hardening phase transition into TZP is extremely high resulting (at an optimal structure) in extra high mechanical characteristics ( $\sigma_{\text {bend }}$ up to $2400 \mathrm{MPa}$ and $K_{1 \mathrm{c}}$ up to 15 MPa $\mathrm{m}^{1 / 2}$ ) [40]. In addition, TZP possesses rather high ionic electrical conductivity; however, it is in- sufficient for the use of the material as solid electrolyte. TZP composites were tested as tool materials, the production of such instruments is reported in EU and in Russia [40-42].

\subsection{Graphene additions}

Graphene is usually treated as a sheet of interconnected regular hexagons. The characteristics of these hexagons are: $\mathrm{sp}^{2}$-hybridized carbon atoms in the hexagon vertices; the hexagon edge length of $0.142 \mathrm{~nm}$, and C-C-C plane angle of $120^{\circ}$. Generally, graphene can be interpreted as a graphite monolayer separated from the bulk.

Graphene in the above discussed form is rarely used for composite synthesis due to the following reasons. The excess free surface energy of the material results in its instability; it also gives rise to agglomeration and folding [43,44]. In additions, the approaches used for pure graphene production involve the necessity of some substrate; graphene is usually closely connected with such a substrate.

As an alternative to pure $\mathrm{Gr}$, graphene derivatives are usually used to produce Gr-containing composites (see Fig. 1): Gr-nanoplatelets and nanoribbons, as well as so-called graphene oxide $(\mathrm{GrO})$ and reduced graphene oxide - $(\mathrm{rGO})$. Let us discuss the in some more detail.

Graphene nanoplatelets - GNPs. GNPs are usually the sheets consisting of $\mathrm{Gr}$ monolayers with the typical linear dimensions $\sim 20 \times 20 \mu \mathrm{m}$ and a number of Gr monolayers from 1 to 10 . GNPs tend 

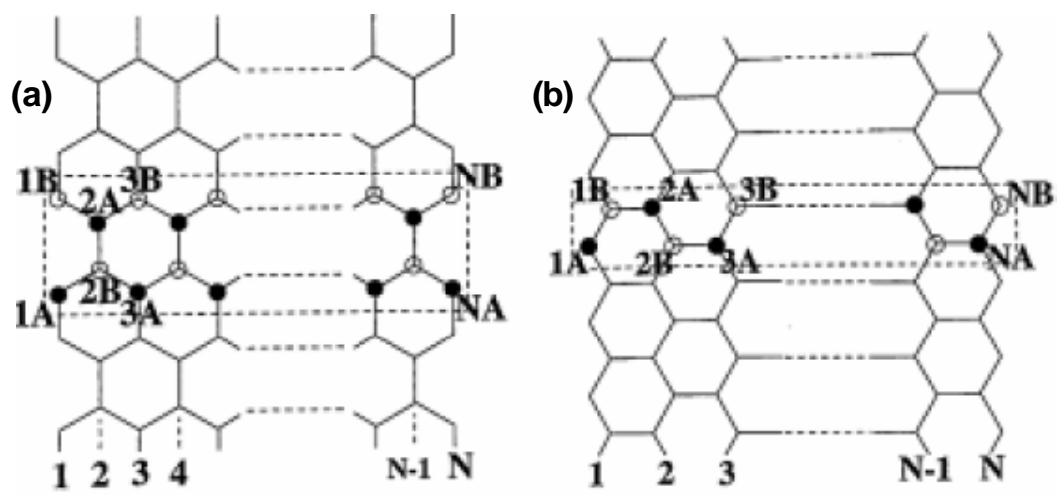

Fig. 2. The structure of the terminal atoms in the graphene nanoribbons: (a) chair and (b) zig-zag, adapted from [52].

to agglomerate possessing high specific surface area being $400-700 \mathrm{~m}^{2} / \mathrm{g}$ [48]. Note that the above area is very high, however, it is much less than those calculated theoretically for pure $\mathrm{Gr}-2630 \mathrm{~m}^{2} / \mathrm{g}$. Since the linear dimensions of GNPs is rather low, relatively high number of unsaturated terminal carbon atoms are present here; they are easily connected with each other, with another atoms or with functional dopant groups, strongly affecting the basic GNPs properties, foremost, electrical conductivity [49-51]. GNPs are usually produced by intercalation approaches or by mechanical delamination in the mills in the liquid ambient, in an inert gas, or in the air.

Graphene nanoribbons - GNRs. GNRs are the graphene sheets with the width less than $50 \mathrm{~nm}$ (up to 20 hexagons), usually they are produces by carbon nanotubes unfolding [46], other approaches are quite rarely used. GNRs possess very interesting properties: in contrast to GNPs, their electrical and optical characteristics depend on the type of hexagon package in the Gr sheet, see Fig. 2 [57].

Two GNR modifications are considered depending on hexagons package in the ribbon, "chair" modification is shown in Fig. 2a and "zig-zag" modification in Fig. 2b. Theoretical modeling of GNRs properties showed that metal properties could be expected for "zig-zag" modification, while the "chair" could have either metal or semiconductor properties, [53-56] (Fig. 3). At that, experimental data on GNRs are fairly contradictive.

Graphene oxide - GrO. GrO is a graphene sheet with the oxygen introduced in the form of carboxyl, epoxy, and hydroxyl groups. GrO is usually manufactures by graphite oxidation under the harsh conditions (so-called Hammer's method [57]). As a result of such oxidation, the interplane distance between the graphite monolayers increases from 3.35 $\AA$ up to $7 \AA$. Further mechanical, thermal or ultra- sound treatment brakes the bonds between the monolayers providing graphene-like structures. The basic $\mathrm{GrO}$ advantages are the production simplicity and the possibility of its water dispersion in contrast to organic solvents used for nanoplatelets and nanoribbons. In turn, the main drawback of the material is its low conductivity not allowing to use it as an electron conductor in the composites.

Reduced graphene oxide - rGrO. Graphene oxide subjected to reduction is called the reduced graphene oxide, usually the reduction is carried out thermally or by some strong reducing agents (hydrazine, sodium borohydride, etc.) [58]. Such a reduction partially increases the electron conductivity of the material. However, till now, no approach providing the complete regeneraton of the graphene structure has been suggested.

Summarizing the above consideration, one can conclude that zirconia cubic solid solutions possess high ionic conductivity, but their mechanical characteristics are significantly lower than that typi-
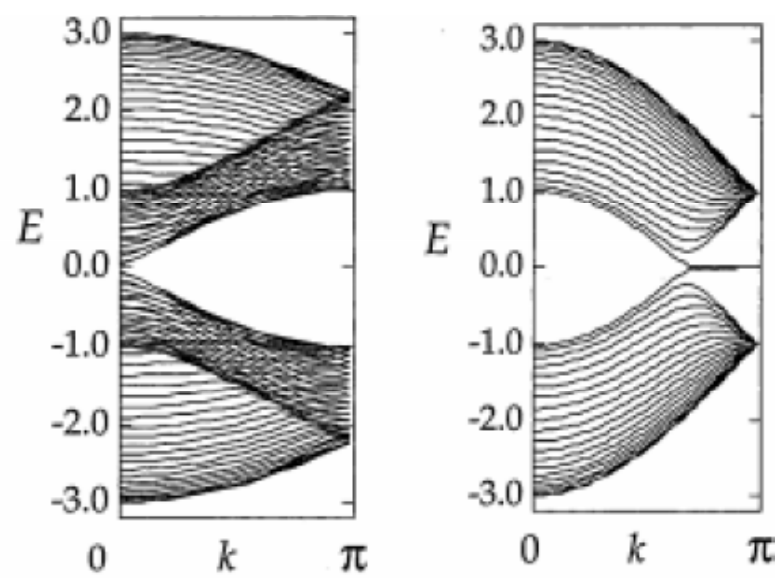

Fig. 3. Zone structure in the graphene nanoribbons for the : (a) chair structure and (b) zig-zag structure with $N=20$, adapted from [52]. 


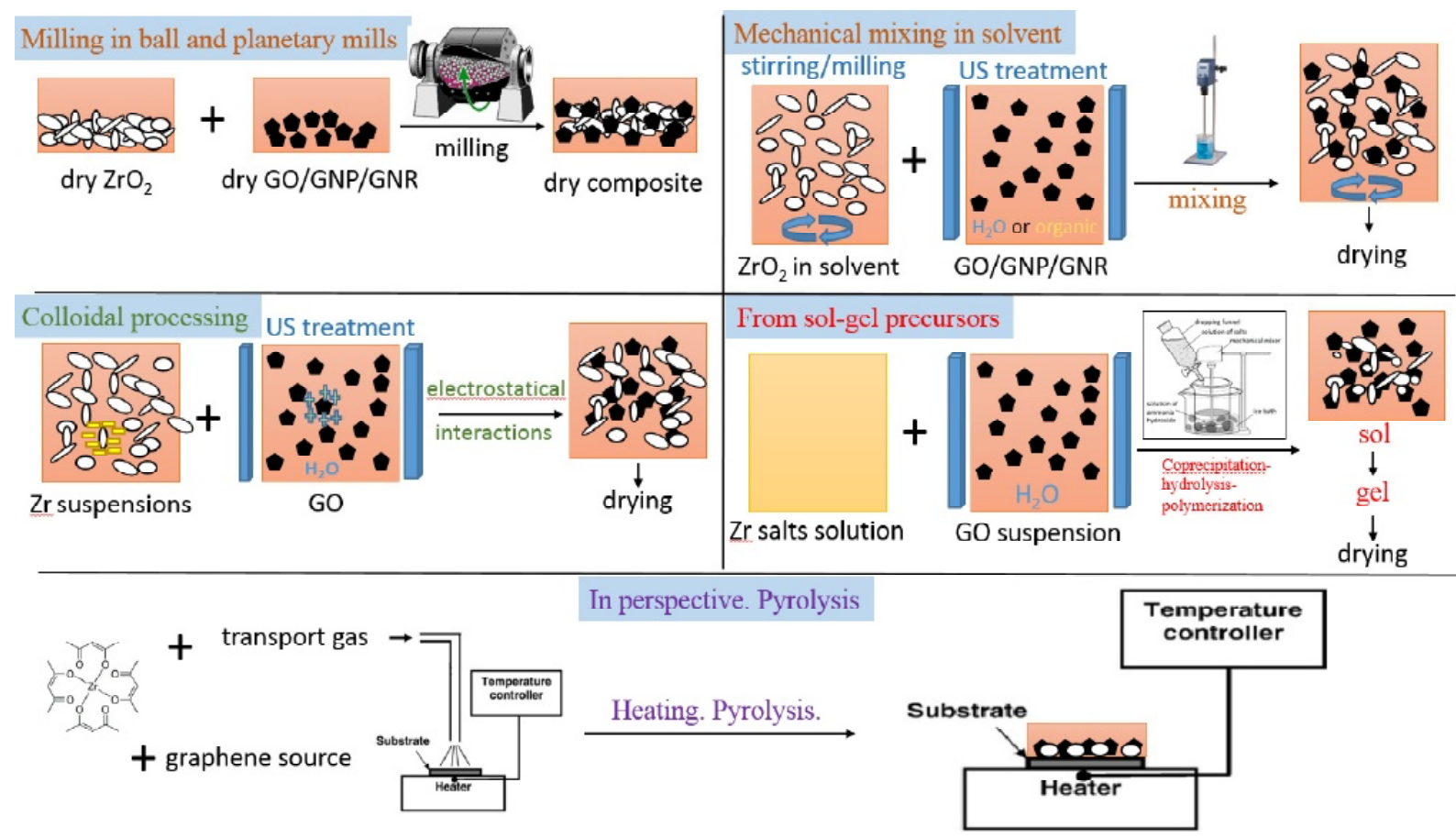

Fig. 4. Mechanisms applied for the precursor powder homogenization, based on data reported in $[47,59]$.

cal for tetragonal or partialy stabilized zirconia. In turn, high mechanical properties of TZP are usually due to martensitic hardening and monoclinic phase formation resulting in the material instability: indeed, slow TZP destruction is observed in a water-containing ambience. The possible pathway to develop new composites free of the above discussed drawbacks is the introduction of graphene or Gr-containing additives with high mechanical properties into the zirconia matrix. The key point of this approach is the procedure of $\mathrm{Gr}$-containing additions since this procedure determines both the final composite structure and the uniform additive distribution in the oxide matrix. Let us consider these approaches in more detail.

\subsection{Approaches to the Gr-containing additions dispersing in the zirconia matrix}

Similarly to the approaches used for the ceramic composites sintering, manufacturing of $\mathrm{ZrO}_{2}$-Gr composites could be considered as containing the following main steps: (i) manufacturing of the homogeneous precursor powder for the composite; (ii) powder compacting, and (iii) baking. There are a number of possible pathways to obtain the uniform distribution of the Gr-containing additive in the ceramic precursor powder, see Fig. 4.

- Joint zirconia and Gr-additive milling in ball or planetary mills. This approach is cheap and quite available to mix zirconia powders with Gr-additives and to get proper uniform distribution of the additive. Ball and planetary mills as well as mechanical agitators [60] are used here. Rather high process temperatures could be obtained during the milling in the dry state (without wet binders); that high temperature treatment additionally promotes partial GrO reduction.

- Mechanical mixing in the solvent ambience. Note that mixing could take place in the dry form as well as in solvent ambience. The dispersion of the Gr-additive and the ceramic precursor powder in the liquid may be performed in one vessel as well as separately. Water (for GrO) [61] or organic liquids (for GNP, GNR, and rGrO) [62] are usually used as solvents here. Authors of [63] investigated the effect of $3 \mathrm{~mol}$.\% yttria-stabilized tetragonal zirconia (3YTZP) ceramic matrix with GNP mixing approach on the structure and properties of the composites manufactured by spark plasma sintering (SPS).

Summarizing the results reported in [63], one can conclude that, in spite of the fact that the obtained density for all samples studied was close to theoretical one, the effect of mixing approach was quite evident. GNPs with the significant surface area mainly oriented in the direction perpendicular to the compression axis were observed in the composites synthesized from powders mixed by ultrasound or ball milling in a planetary mill in the isopropyl alcohol presence, i.e. by "wet" mixing. The above GNPs shape and orientation resulted in some significant 
anisotropy of the composite properties. On the contrary, composites synthesized from the powders mixed by "dry" approach showed smaller GNPs dimensions and lower monolayers number. As a result, GNPs were able to "adapt" to the structure of the ceramic matrix covering its grains. In this case, uniform GNPs distribution in the composite matrix is observer and the composite properties are isotropic.

- Homogenization using colloid systems. This approach is based on the use of stable $\mathrm{ZrO}_{2}$ suspensions possessing negative surface charge. The addition of the GrO suspension characterized by positive surface charge leads to the stable agglomerates formation due to electrostatic interactions. Well mixed precursor powders could be obtained here after the solvent removal.

- Sol-gel processes. Sol-gel processes are widely used to synthesize oxide powders, they are based on the hydrolysis of soluble substances resulting in the formation of non-soluble hydroxides (sols). Sols could be transferred to gels and, after the water removal, to monodispersed powders. In case of zirconia, soluble $\mathrm{ZrO}_{2}$-containing compounds are precipitated in the form of $\mathrm{Zr}(\mathrm{OH})_{4}$ sol; it is transferred into gel and the residual water is removed. The final product here is $\mathrm{ZrO}_{2}$ powder. The advantage of the process is the possibility to vary the process conditions obtaining the required powder particles size (from $10 \mathrm{~nm}$ [60]), in addition, the approach is rather simple. Sol-gel synthesis can be used to manufacture $\mathrm{Zr}$-based graphene-containing precursor powders. The precipitation here is carried out in the suspension of the Gr-containing additive, GrO-water suspension is usually used here. Note that the Gr-containing particles in such an approach could act as crystallization centers, hence, the obtained particles could be larger than in the case of pure sol-gel process.

- Alkoxides pyrolysis. Theoretically, alkoxides pyrolysis is an alternative approach to manufacture wee-mixed precursor powders. We have not found works describing the application of this method to Zr-based Gr-containing composites production; however, its application to $\mathrm{ZrO}_{2}$ compounds was reported in $[59,64,65]$. Authors of [59] showed the possibility to produce well-formed nanostructured yttrium stabilized zirconia (YSZ) with a high conductivity using the pyrolysis of aerosol mixture containing the following acetylacetonates: $0.025 \mathrm{M} \mathrm{Zr(acac})_{4}$ and $0.01 \mathrm{M} \mathrm{Y}(\mathrm{acac})_{3}\left(\mathrm{H}_{2} \mathrm{O}\right)_{x}$, silicon substrate was used here. It is expected that further modification of this approach could make it more competitive.
Summarizing the above consideration, we can state that all the approaches used for the homogenization of $\mathrm{Gr}$-containing Zr-based precursor powders possess advantages and drawbacks; no one can be assumed as an ideal one. However, one can expect better results using sol-gel approaches or "dry" mixing.

\subsection{Zr-based ceramics compacting and baking}

As was mentioned above, the next steps of the composite synthesis are compacting and baking. Spark plasma sintering coupling both processes is one of the most perspective approaches here, this method bases on pressing with simultaneous Joule heating under electric current. At that, the press is also the current conductor here [66]. Pressing is usually carried out in the graphite press-forms which also are the current conductors. Sometimes, the refractory metal foil is added as an interlayer simplifying further sample from press-form separation. Obviously, the process should be carried in vacuum or in inert atmosphere to prevent press-forms oxidation at elevated temperatures. Both direct and alternating currents are used in SPS method, some approaches use impulse or another less common regimes.

SPS approach is fairly different for conductive and non-conductive materials due to the difference in heating mechanisms. Conductive samples are heated by electric current passing through the sample bulk, while non-conductive samples are heated via the convective mechanisms, the press-form here acts as a heat source.

Note that $\mathrm{Zr}$-based matrix is a non-conductive material and $\mathrm{Gr}$-containing additive is a conductive one, both heating mechanism could be expected during $\mathrm{ZrO}_{2}$-graphene composites production be SPS approach. As a result, non-uniform heating could be expected here.

The basic advantage of SPS method is a high heating rate determining rather short synthesis duration (usually, it is some minutes); this is a real advantage in a work with nanopowders since the short process time provides an opportunity to retain their unique properties. In addition, no processes are taking place in the ceramic matrix, so, the grain growth is prevented. Another advantage of the method is the possibility to get the ceramics density close to the theoretical one. In addition, vacuum or inert gas atmosphere prevents the Gr-containing additive oxidation. 


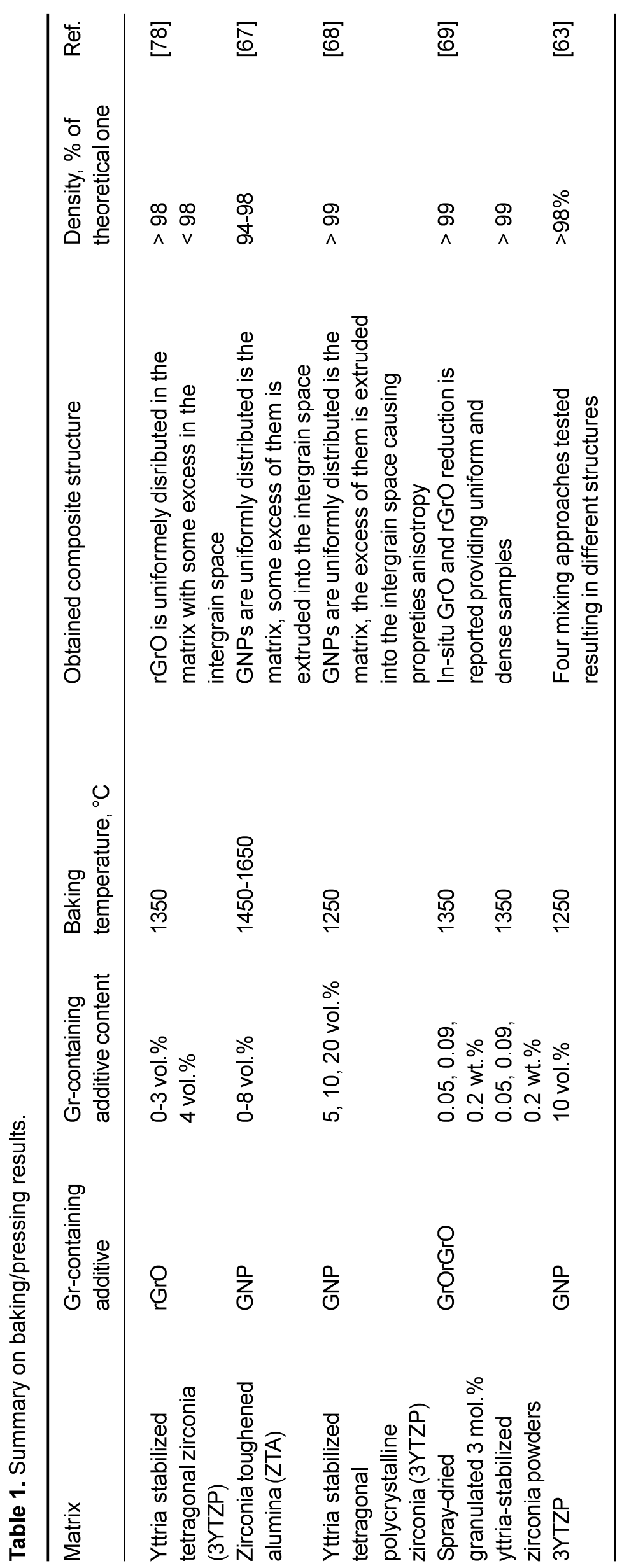


The drawbacks of the method are non-isostatic pressing leading to the anisotropy of the final material and non-uniform heating resulting in cracking and non-uniform baking.

Some alternative compacting and baking approaches are used sometimes: hot pressing, hot isostatic pressing, baking in vacuum without pressing, convective baking in air ambience, etc. These approaches possess some advantages; however, process duration and energy consumption typical for them make them noncompetitive compared to SPS approach.

Let us discuss the results reported in modern literature in some more detail, see also Table 1. Paper [78] reported SEM results for 3YTZP matrix (with 3 mol. $\% \mathrm{Y}_{2} \mathrm{O}_{3}$ ) reinforced with 0.6,1.8.3.0, and $4.1 \mathrm{vol}$ \% of rGrO; pure 3YTZP was used as a reference sample. It was shown that is possible to obtain sample density being as high as $98 \%$ of the theoretical one. The increase in the $\mathrm{rGrO}$ additive content gives rise to some small decrease in the sample density. The further increase in graphene additive contents over 4 vol.\% resulted in the significant density decrease indicating the fact that large rGrO contents prevents ceramics densification. The reference sample was characterized by monolithic structure, $\mathrm{ZrO}_{2}$ grains had similar sizes, moreover, linear grain dimensions were similar uniaxially. $\mathrm{rGrO}$ additives were distributed in the intergrain space, the effect of additive extrusion into the intergrain space is more evident at high additive contents.

Authors of [68] investigated the same 3YTZP matrix with high amount of GNP additive of 5,10, and 20 vol.\%; samples were sintered at $1250^{\circ} \mathrm{C}$ by SPS. Similarly to the previous case, GNPs were not destructed during sintering, they were also extruded into the intergrain space. However, the evident GNPs orientation in the direction perpendicular to the pressing axes was observed, this type of GNPs orientation negatively affect electrical properties of the material. The regions with maximal GNPs concentration were clearly observed at the maximal Grcontaining additive contents of $20 \mathrm{vol} . \%$.

GNPs were also used as Gr-containing additives in [67], they were introduced in zirconia hardened $\mathrm{Al}_{2} \mathrm{O}_{3}$ matrix. Similarly to the above discussed work, GNPs were uniformly distributed in the ceramic matrix; the extrusion of Gr-additives in the intergrain space was stated; the material had the density close to the theoretical one. The same trend for density decrease at GNPs contents increase was shown. It should be noted that rather high sintering temperature of $1650{ }^{\circ} \mathrm{C}$ did not destroy graphene nanoplatelets.
Authors of [69] investigated 3YTZP composites with $0.05,0.09$, and 0.2 wt. $\%$ GrO contents. In addition, they performed SPS synthesis using the preliminary reduced $\mathrm{ZrO}_{2}$-GrO powders in argon atmosphere at $850^{\circ} \mathrm{C}$; SPS synthesis was performed at $1350^{\circ} \mathrm{C}$. Composite density close to the theoretical one (>99) was obtained for both material type (with $\mathrm{GrO}$ and preliminary reduced $\mathrm{GrO}$ ), graphene nanosheets were detected in the intergrain boundary of the final composite. Similarity of the results obtained for both additives type gives an opportunity to conclude that preliminary $\mathrm{GrO}$ reduction (i.e. rGrO formation) does not significantly affect on final composite properties. It should be mentioned that authors of [70] reported similar effect - GrO reduction to $\mathrm{rGrO}$ in SPS process.

Summarizing the above discussion, one can state that SPS approach provides manufacturing of dense composites with the density close to the theoretical one (98-99\%) and with the uniform distribution of graphene-containing additives in the ceramic matrix. However, information on the effect of the additive type and its contents and the composite properties is still insufficient.

\section{3. $\mathrm{ZrO}_{2}$-Gr COMPOSITES CHARACTERIZATION}

\subsection{Mechanical properties}

At the moment, there are a lot of works dealing with mechanical characteristics of $\mathrm{ZrO}_{2}$-Gr microstructure with different microstructure: porous, non-porous, lamellar, etc. [69,71-79].

Authors of [78] studied the properties of 3YSZrGrO composite produced by SPS approach. Vickers hardness and crack resistivity data are presented in Fig. 5 as a function of $\mathrm{rGrO}$ contents. It was shown that composite hardness slowly decreases with the increase in $\mathrm{rGrO}$ concentration; on the contrary, the crack resistivity is increasing. The increase in the composite hardness is usually explained by grain size decrease, see, e.g. [80]. Since the average grain size in the produced composites also decreases with the $\mathrm{rGrO}$ contents increase, the observed hardness behavior could not be assumed as being due to the grain size effect, but it can be discussed through decreasing in the bulk density (residual porosity increasing) at $\mathrm{rGrO}$ addition [81].

Significant density decrease is also observed for some other ceramics-graphene composites [82]. Crack resistivity of monolithic $3 \mathrm{YSZ}$ itself is rather low (4.4 MPa $\left.{ }^{1 / 2}\right)$, authors of [78] assumed this effect as being due to low average grain size [85]. 


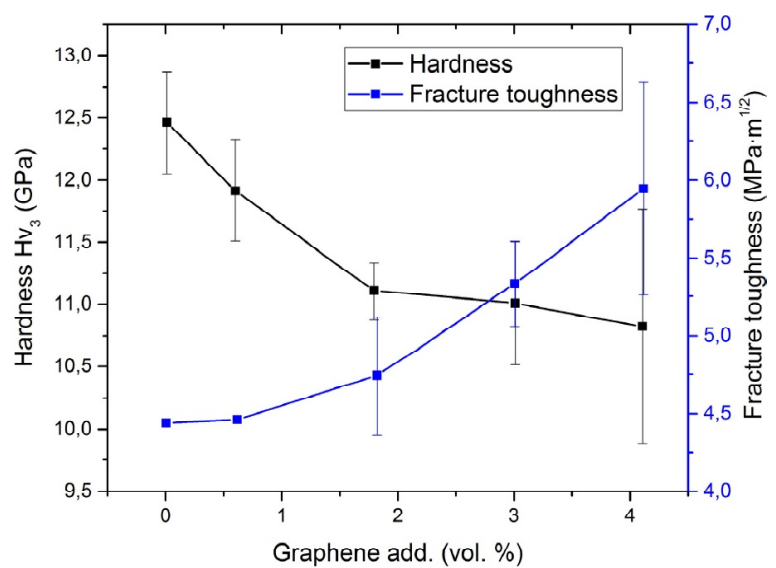

Fig. 5. Vickers hardness and crack resistivity of $3 Y S Z$ ceramics produced by SPS approach vs $r G r O$ contents, data reported in [78].

The introduction of $4.1 \mathrm{vol} . \% \mathrm{rGrO}$ leads to the significant crack resistivity increase up to $5.9 \mathrm{MPa}$ $\mathrm{m}^{1 / 2}$; note that the effect is more evident than in the case of single wall CNT addition. Authors of [78] suggested that the nature of this effect is based on zirconia grains folding by $2 \mathrm{D}$ graphene nanosheets [83].

The comparison of the results reported in [78] and [84] is fairly interesting. Similar 3YSZ ceramic matrix was used with the same Gr-containing additive (GNP). The difference was in the synthesis approach only: the authors of [78] were using SPS approach, while plasma assisted sintering (PAS) was used in [84]. The basic difference of PAC procedure is the impulse current regime promoting the evaporation of impurities from the particle surface. The results on the mechanical characteristics of the obtained composites - microhardness and crack resistivity (measured by single-edge notched beam method) along with the data on the composites relative density obtained in [84] are demonstrated in Table 2. As seen from the table, the characteristics of the composites produced using PAS approach are higher than that presented in [78]; in particular, crack resistivity values were increased up to 8.9-9.5 MPa $\mathrm{m}^{1 / 2}$ for pure $3 \mathrm{YSZ}$ and up to $15.3 \mathrm{MPa}$ $\mathrm{m}^{1 / 2}$. for graphene-containing composites (Fig. 6), the increase in crack resistivity here can be estimated as $\approx 60 \%$. In turn, sample hardness also demonstrates some increase, the authors of [84] explain this fact by crack deflection, crack bridging and microcrack formation.

Results reported in [84] were argued in [86]. The authors of [86] considered that Gr-containing addition does not affect significantly the mechanical properties of the composite, in particular, the above mentioned mechanisms concerning crack and microcrack behavior were criticized. It was assumed that graphene additive acts as some lubricant and all positive effects deal with this effect only.

$\mathrm{GrO}$ and carbon nanofibers (CNFs) were used as carbon additions in [86], synthesis procedure was similar to those described in [78]. It was shown that the crack length in case of monolithic $\mathrm{ZrO}_{2}$ and in case of carbon-containing composites is quite close, while crack resistance changes are within the experimental error limits for all samples studied, see Table 3.

\subsection{Electrical characteristics}

Introduction of graphene or Gr-containing additives should increase composite conductivity, however, the exact results strongly depend on the synthesis approach. Paper [87] reports 2 vol.\% of GrO addition to the mixed $\mathrm{ZrO}_{2}-\mathrm{Al}_{2} \mathrm{O}_{3}$ ceramics. As a result, resistivity decrease of $10 \pm 1.0 \Omega \mathrm{cm}$ was achieved, this result is four orders of magnitude lower than that obtained at CNFs addition $\left(2.510^{4} \Omega \mathrm{cm}\right)$ and 9 orders of magnitude lower than in case of pure zirconia [88].

Table 2. Mechanical properties and the relative densities of zirconia-graphene composites obtained by PAS approach, data from [84].

\begin{tabular}{lllll}
\hline $\begin{array}{l}\text { Graphene } \\
(\text { wt. \%) }\end{array}$ & $\begin{array}{l}\text { Temperature } \\
\left({ }^{\circ} \mathrm{C}\right)\end{array}$ & $\begin{array}{l}\text { Relative density } \\
(\%)\end{array}$ & $\begin{array}{l}\text { Hardness } \\
(\mathrm{GPa})\end{array}$ & $\begin{array}{l}\text { Fracture toughness } \\
\left(\mathrm{MPa} \cdot \mathrm{m}^{1 / 2}\right)\end{array}$ \\
\hline 0 & 1200 & 97.5 & 11.36 & 8.9 \\
0 & 1300 & 99.2 & 12.46 & 9.5 \\
0 & 1400 & 99.1 & 10.95 & 9.0 \\
0.01 & 1200 & 98.9 & 13.56 & 11.2 \\
0.01 & 1300 & 99.4 & 12.33 & 15.3 \\
0.01 & 1400 & 99.3 & 12.69 & 9.3 \\
0.03 & 1300 & 99.2 & 12.58 & 13.5 \\
0.05 & 1300 & 98.9 & 13.02 & 10.5 \\
\hline
\end{tabular}


Table 3. Mechanical properties and crack characteristics for $\mathrm{ZrO}_{2}$ ceramics with graphene and carbon additive, data from [86].

\begin{tabular}{lllll}
\hline Sample & $\begin{array}{l}\text { Crack characteristic } \\
\text { (the size of the } \\
\text { indention) } 2 \mathrm{a}(\mu \mathrm{m})\end{array}$ & $\begin{array}{l}\text { Crack characteristic } \\
\text { (twice the length of } \\
\text { the crack+ the size } \\
\text { of the indention) } \\
2 \mathrm{c}(\mu \mathrm{m})\end{array}$ & Hardness $(\mathrm{GPa})$ & $\begin{array}{l}\text { Fracture } \\
\text { toughness } \\
\left(\mathrm{MPa} \cdot \mathrm{m}^{1 / 2}\right)\end{array}$ \\
\hline $\mathrm{ZrO}_{2}$ & $112 \pm 1$ & $264 \pm 2$ & $15.7 \pm 0.2$ & \\
$\mathrm{ZrO}_{2}-\mathrm{GO}$ & $114 \pm 1$ & $260 \pm 6$ & $15.0 \pm 0.2$ & $5.6 \pm 0.1$ \\
$\mathrm{ZrO}_{2}-\mathrm{CNFs}$ & $115 \pm 1$ & $257 \pm 6$ & $14.7 \pm 0.2$ & $5.3 \pm 0.3$ \\
\hline
\end{tabular}

The effect of synthesis approach on the composite conductivity can be illustrated by Fig. 7. As was discussed above, SPS synthesis could significantly decrease $\mathrm{ZrO}_{2}$-Gr composite resistivity; but, the significant anisotropy can be seen: indeed, at lower GNP contents $\sigma_{\| \prime}$ and $\sigma_{\perp}$ values are fairly different. Note that this effect does not manifest itself at the maximal GNP contents of $20 \mathrm{vol} . \%$ [68]. As it was mentioned above, this effect is attributed to GNPs orientation that is perpendicular to the compression axis. Anisotropy coefficient could achieve rather high values: basing on results of [68] it can be calculated as $\sigma_{\|} / \sigma_{\perp}=6.84 \pm 0.11$ for the sample with 10 vol.\% of GNPs. Note that the same ratio for the sample with 5 vol. $\%$ of GNPs is $3.36 \pm 0.05$; hence, one can consider the evident dependence of the resistivity on $\mathrm{Gr}$-containing additive contents. This effect is usually assumed as being due to the bonds formation between GNP nanosheets in the $a b$-plane similar to the case of highly oriented pyrolitic graphite $[89,90]$ and graphite monocrystal [91]. The significant increase of $\sigma_{\|}$input is observed

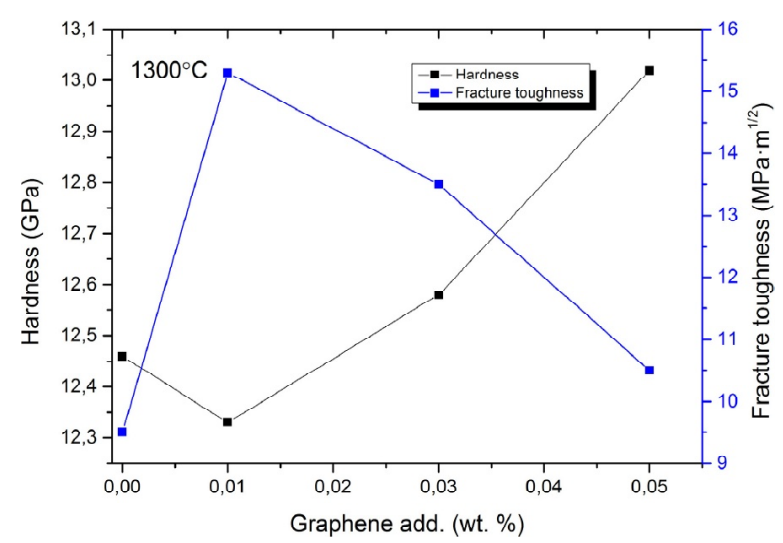

Fig. 6. Mechanical characteristics (hardness and crack resistivity) of the zirconia-graphene composites (3YSZ-GNP) synthesized by PAS approach [84]. at 20 vol.\% of GNPs, it decreases anisotropy factor down to $1.18 \pm 0.05$. In fact, material becomes isotropic here and 3D GNP network is formed.

Similar behavior is typical for other ceramic matrixes [92-95]. However, it should be mentioned that the maximal conductivity value $\left(\sim 276 \mathrm{~S} \mathrm{~m}^{-1}\right)$ obtained in [68] for zirconia matrix is much lower than that shown for $\mathrm{Al}_{2} \mathrm{O}_{3}$-GNP composites $(\sim 1000$ $\mathrm{S} \mathrm{m}^{-1}$ at 15 vol. $\%$ of GNPs) in [96] and $\mathrm{Si}_{3} \mathrm{~N}_{4}-\mathrm{GNP}$ composites ( $4378 \mathrm{~S} \mathrm{~m}^{-1}$ at 25 vol.\% of GNPs) in [93]. However, this effect is probably not due to the matrix, but to the Gr-containing additive characteristics: number of monolayers, synthesis approach, agglomeration, etc.

Note that most of the papers discussing $\mathrm{ZrO}_{2}-$ Gr composites discuss composites based on tetragonal $\mathrm{ZrO}_{2}$ matrix. However, other zirconia modifications and, in particular, cubic $\mathrm{ZrO}_{2}$ could be also treated as being very promising. The possibility to

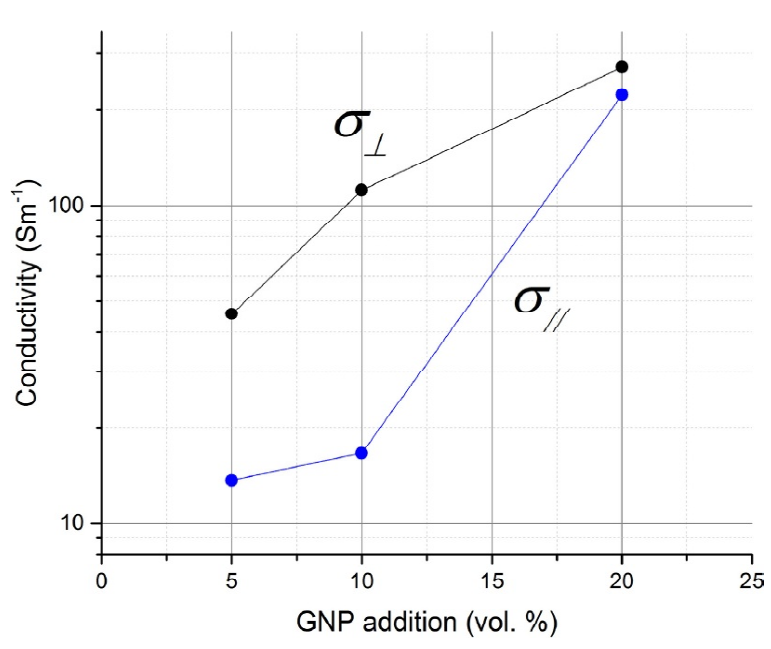

Fig. 7. Illustration of the electrical resistivity anisotropy in the 3YSZ-GNP composites with varying $\mathrm{Gr}$-addition contents, measurements at room temperature, image based on results reported in [68]. 


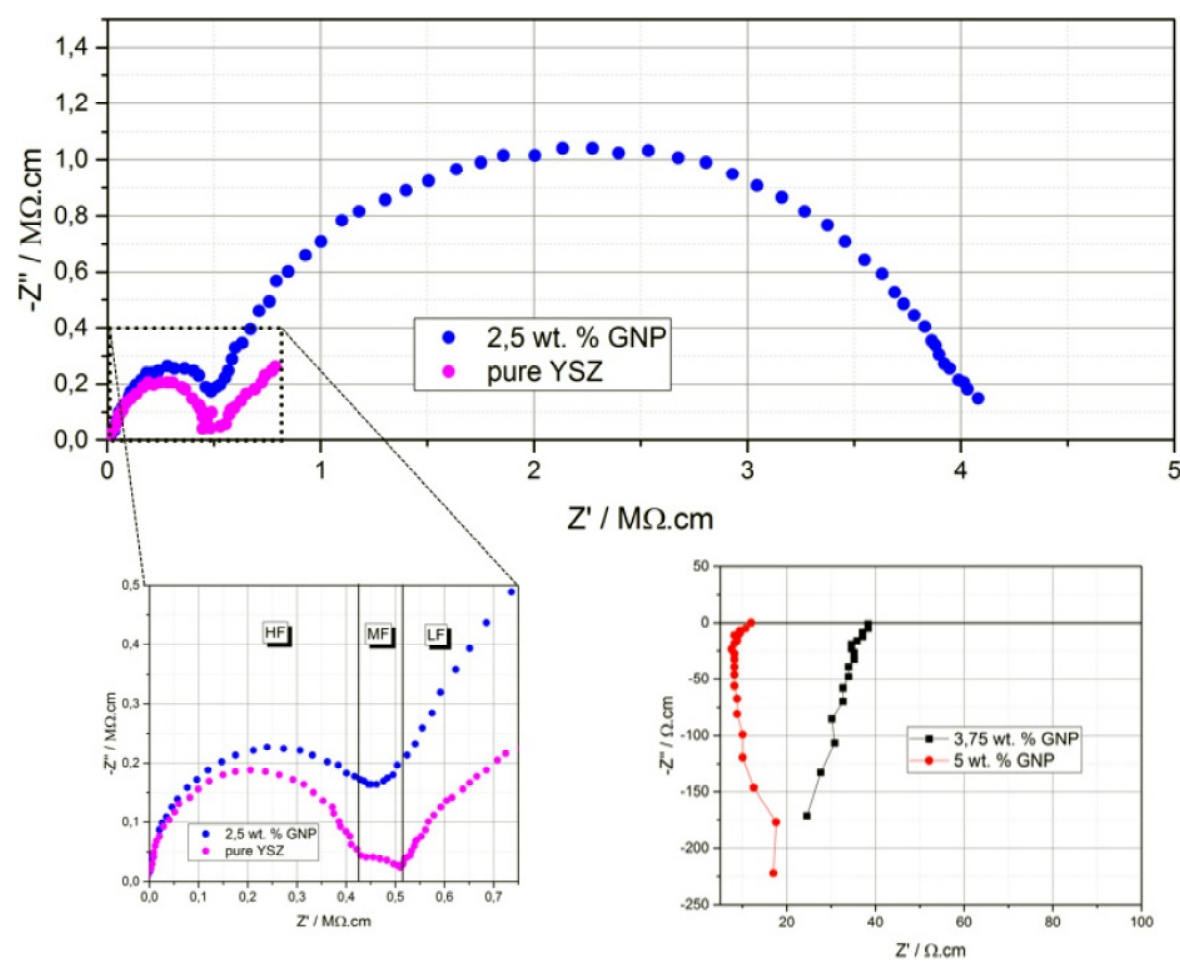

Fig. 8. Electrochemical impedance spectra of the electrochemical impedance for YSZ-GNP samples: (a) 2.5 wt.\% GNP, (b) 3.75 wt.\% GNP, and (c) 5.0 wt.\% GNP, replotted from [99].

combine high electronic conductivity typical for graphene with ionic conductivity and high thermal stability of the cubic zirconia are very attractive for different applications.

Let us discuss the mechanism of cubic fluoritelike zirconia conductivity in some more detail. Yttrium oxide $\mathrm{Y}_{2} \mathrm{O}_{3}$ is usually added to stabilize cubic zirconia, the conventional amount of such additive is 8-9 mol.\% [97], this composition is known as yttria stabilized zirconia YSZ). YSZ ion conductivity appears due to heterovalent substitution of $\mathrm{Zr}^{4+}$ by $\mathrm{Y}^{3+}$ ion; the difference is charge is compensated by the formation of oxygen vacancies; the process is described by Kröger-Vink notation (1).

$$
\mathrm{Y}_{2} \mathrm{O}_{3} \stackrel{\mathrm{ZrO}_{2}}{\longrightarrow} 2 \mathrm{Y}_{\mathrm{Zr}}^{\prime}+3 \mathrm{O}_{0}^{\times}+\mathrm{V}_{0} \text {. }
$$

Double charged oxygen vacancies are characterized with high mobility and can migrate into the material bulk exchanging with oxygen ions via cocalled "jump" mechanism [98] .

At the moment (year 2018) only one work reporting the detailed study of the electrical properties of cubic YSZ-GNP composites as a function of temperature is available [99]. Composites containing 2.5, 3.75, and $5.0 \mathrm{wt} . \%$ GNP were synthesized by SPS. Both pure YSZ and the composite with minimal GNP contents (2.5 wt.\%) were possess dominant ionic conductivity (volume and surface components) at a temperature range $500-900 \mathrm{~K}$ (Fig. 8). Some small deviations in the electrochemical impedance spectra can be due to some changes in the intergrain space: graphene nanosheets are appearing there preventing the electrical charge transfer between the grains. The values of the activation energy measures for these samples coincide within the limits of the experimental error and can be estimated as $E_{a}=1.1 \mathrm{eV}$. Such a value of activation energy is typical for oxygen conductivity realized via "jump" mechanism.

At the increase in the graphene-containing additive contents, the composite conductivity increases by four orders of magnitude, this effect is also observed for the sample with a maximal GNPs contents of $5 \mathrm{wt} . \%$. At that, the value of the activation energy decreases down to $0.1 \mathrm{eV}$. Since the behavior of the electrical conductivity is well-described by the Arrhenius plot, the measured electrical conductivity can be extrapolated from temperature at which measurements were carried out to room temperature where the difference in the conductivities is expected to be increased by 11 orders of magnitude. Note that the produced composites appeared to be stable under the reduction atmosphere $\left(p_{02}\right.$ $<10^{-5} \mathrm{~atm}$.), but they are unstable in air, see Fig. 9 . Indeed, the sample conductivity (Fig. 9b) drastically decreased after the exposition at $500^{\circ} \mathrm{C}$ for 13 hours. 
a)

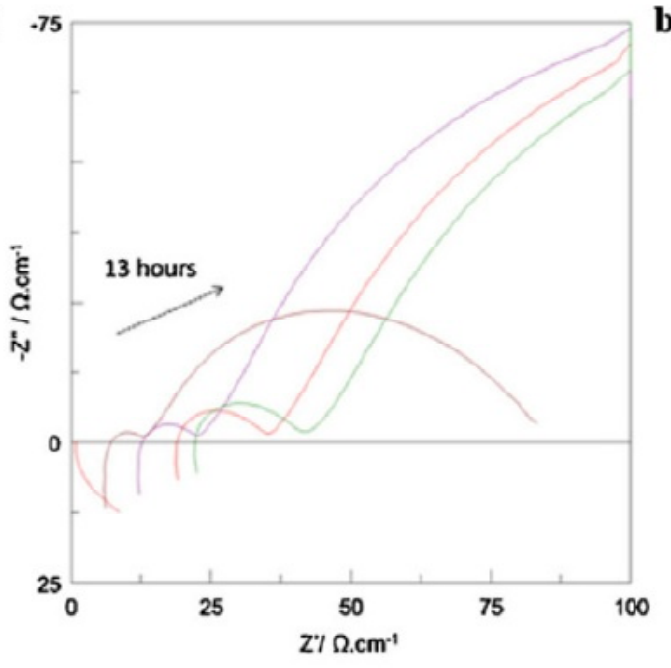

b)

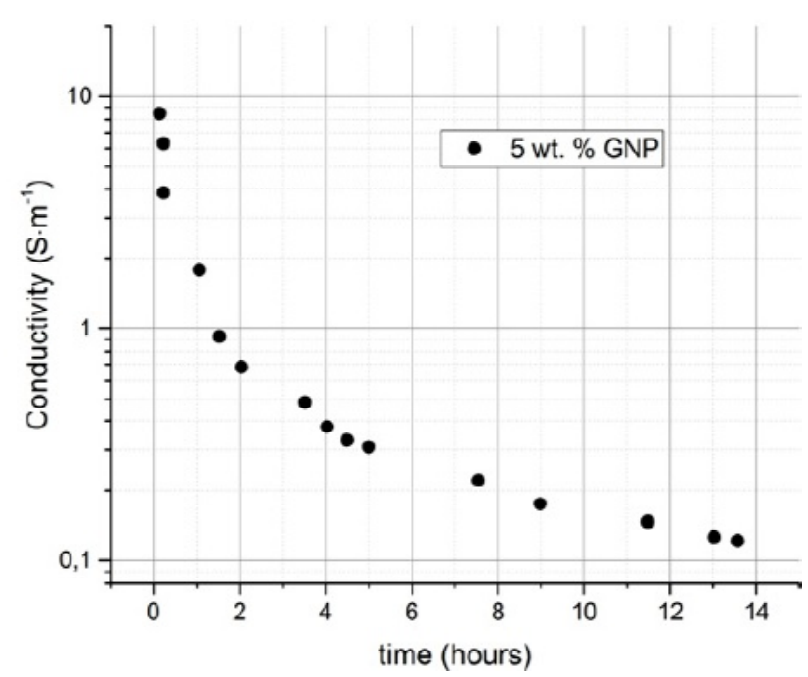

Fig. 9. The effect of YSZ-GNP (5.0 wt.\% GNPs) thermal exposure $\left(500^{\circ} \mathrm{C}, 13\right.$ hours) on (a) electrochemical impedance spectra, (b) electric conductivity, data from [98].

The reason of such decrease can be seen from SEM image of the sample, Fig. 9c, an evident cracking as the result of oxidation can be seen there.

\section{CONCLUSION}

Summarizing the above consideration, one can state that mechanical charactestics of $\mathrm{ZrO}_{2}$-Gr composites are well studied, especially for the case of tetragonal matrix modification. Generally, the limits of their application are clear. However, the perspective possibility to use such composites as functional high-temperature materials (cathodes and anodes in solid-oxide fuel cells (SOFC) or membranes in oxygen pumps) is still questionable, additional studies are necessary here.

The another non-zirconia materials developed nowadays (perovskite-like high temperature mixed conductors) possess significant drawbacks, the basic of them is a low stability in reducing atmosphere $[100,101]$ due to partial oxide reduction with further phase lamination.

As it was shown above, carbon component of the discussed compsiotes oxidizes at temperatures $>700^{\circ} \mathrm{C}$ being even low than the working temperature of most SOFC elements during the exposure for some hours. So, one of the general tasks of the further investigations should be the increase of the composites oxidation resistance.

Additional investigations are also necessary to clarify the effects of the Gr-containing additive type and synthesis approach on the composites characteristics. The available information here is quite insufficient, in addition, the comparison of the available data is complicated by the fact that different additives are introduced in the different zirconia matrix; moreover, the amount of introduced graphene varies from parts of percent to $10-20 \mathrm{wt} . \%$ and even more.

Systematic study of the effect of composite synthesis on the final state of the graphene-containing additive, flake formation, agglomeration, etc. is also necessary.

\section{ACKNOWLEDGEMENT}

The work was supported by Russian Science Foundation (RSF, project 18-19-00255, Mechanics of bulk functional nanoceramics and ceramic nanocomposites).

\section{REFERENCES}

[1] S. Stankovich, D. A. Dikin, G. H. B. Dommett, K. M. Kohlhaas, E. J. Zimney, E. A. Stach, R. D. Piner, S. T. Nguyen and R. S. Ruoff // Nature 442 (2006) 282.

[2] K.I. Bolotin, K.J. Sikes, Z. Jiang, M. Klima, G. Fudenberg, J. Hone, P. Kim and H.L. Stormer // Solid State Commun. 146 (2008) 351.

[3] S. V. Morozov, K. S. Novoselov, M.I. Katsnelson, F.Schedin, D.C. Elias, J.A. Jaszczak and A.K. Geim // Phys. Rev. Lett. 100 (2008) 016602.

[4] C. Lee, X. Wei, J. W. Kysar, and J. Hone // Science 321 (2008) 385.

[5] A. A. Balandin, S. Ghosh, W. Bao, I. Calizo, D. Teweldebrhan, F. Miao and C.N. Lau // Nano Lett. 8 (2008) 902. 
[6] C. Xu, X. Wang and J. Zhu // J. Phys. Chem. 112 (2008) 19841.

[7] I A Ovid'ko and A G Sheinerman // J. Phys. D: Appl. Phys. 47 (2014) 495302.

[8] V.G. Konakov, O.Yu. Kurapova, N.N. Novik, S.N. Golubev, A.P. Zhilyaev, S.N. Sergeev, I.Yu. Archakov and I.A. Ovid'ko // Rev. Adv. Mater. Sci. 45 (2016) 1.

[9] V.G. Konakov, O.Yu. Kurapova, I.V. Lomakin, I.Yu. Archakov, E.N. Solovyeva and I.A. Ovid'ko // Rev. Adv. Mater. Sci. 44 (2016) 361.

[10] I.Yu. Archakov, V.U. Kazykhanov, V.G. Konakov, O.Yu. Kurapova, A.E. Medvedev, M.Yu. Murashkin, N.N. Novik, I.A. Ovid'ko, E.N. Solovyeva and R.Z. Valiev // Rev. Adv. Mater. Sci. 50 (2017) 13.

[11] A. G. Sheinerman and M. Y. Gutkin // Composite Structures 191 (2018) 113.

[12] M. Hamidinejad, B. Zhao, A. Zandieh, N. Moghimian, T. Filleter and C. B. Park // ACS Appl. Mater. Interfaces 10 (2018) 30752.

[13] T. Kuilla, S. Bhadra, D. Yao, N. H. Kim, S. Bose and J. H. Lee // Prog. Polym. Sci. 35 (2010) 1350.

[14] J. Ma, Q .Meng, A. Michelmore, N. Kawashima, Z. Izzuddin, C. Bengtsson and H.C. Kuan // J. Mater. Chem. A 1 (2013) 4255.

[15] . Zaman H.C. Kuan, Q .Meng, A. Michelmore, N. Kawashima, T. Pitt, L. Zhang, S. Gouda, L. Luong and J. Ma // Adv. Funct. Mater. 22 (2012) 2735.

[16] C. Ramirez, P. Miranzo, M. Belmonte, M. I. Osendi, P. Poza, S. M. Vega-Diaz and M. Terrones // J. Eur. Ceram. Soc. 34 (2014) 161.

[17] M. S. Asl and M. G. Kakroudi // Materials Science and Engineering: A 625 (2015) 385.

[18] C. Zhi, Y. Bando, T. Terao, C. Tang, H. Kuwahara and D. Golberg // Advanced Functional Materials 19 (2009) 1857.

[19] J.-H. Shin and S.-H. Hong // Mater. Sci. Eng. A556 (2012) 382.

[20] R. Poyato, A. Gallardo-López, F. GutiérrezMora, A. Morales-Rodríguez, A. Muñoz and A. Domínguez-Rodríguez // J. Eur. Ceram. Soc. 34 (2014) 1571.

[21] R. K. Chintapalli, F. G. Marro, B. Milsom, M. Reece and M. Anglada // Mater. Sci. Eng. A549 (2012) 50.

[22] A. Datye, K.H. Wu, G. Gomes, V. Monroy, H.T. Lin, J. Vleugels and K. Vanmeensel // Compos. Sci. Technol. 70 (2010) 2086.
[23] A. Kasperski, A. Weibel, D. Alkattan, C. Estournčs, C. Laurent and A. Peigney // Ceram. Int. 41 (2015) 13731.

[24] L. Melk, J.J. Roa Rovira, F. García-Marro, M.-L. Antti, B. Milsom, M.J. Reece and M. Anglada // Ceram. Int. 41 (2015) 2453.

[25] A. Duszová, J. Dusza, K. Tomášek, G. Blugan and J. Kuebler // J. Eur. Ceram. Soc. 28 (2008) 1023.

[26] J.-H. Shin and S.-H. Hong // Mater. Sci. Eng. A556 (2012) 382.

[27] T. Ukai, T. Sekino, A.T. Hirvonen, N. Tanaka, T. Kusunose, T. Nakayama and K. Niihara // Key Eng. Mater. 317-318 (2006) 661.

[28] R. Poyato, J. Macías-Delgado, A.Gallardo-López, A. Muńoz and A. Domínguez-Rodríguez // Ceramics International 41 (2015) 12861

[29] J. Chevalier // Biomaterials 27,(2006) 535

[30] J. Chevalier and L. Gremillard // J. Eur. Ceram. Soc. 29 (2009) 1245.

[31] O. Y. Kurapova and V. G. Konakov // Rev. Adv. Mater. Sci. 36 (2014) 177.

[32] G. I. V. Carbajal, J. L. R. Galicia, J. C. R. Ángeles, J. L. Cuevas and C. A. G. Chavarría // Ceram. Int. 38 (2012) 1617.

[33] R. C. Garvie, R. H. Hannink and R. T. Pascoe // Nature 258 (1975) 703.

[34] S. Akbar, P. Dutta and C. Lee // Int. J. Appl. Ceram. Technol. 3 (2006) 302.

[35] N. N. Novik, O. V. Glumov, S. N. Golubev, V. G. Konakov and I. Yu. Archakov // Rev. Adv. Mater. Sci. 43 (2015) 67.

[36] S. M. Shugurov, O. Y. Kurapova, S. I. Lopatin, V. G. Konakov and E. A. Vasil'eva // Rapid Communications in Mass Spectrometry 31 (2017) 2021.

[37] A. H. Heuer // J. Am. Ceram. Soc. 70 (1987) 689.

[38] G. K. Bansal and A. H. Heuer // J. Am. Ceram. Soc. 58 (1975) 235.

[39] R. C. Garvie and P. S. Nicholson // J. Am. Ceram. Soc. 55 (1972) 152.

[40] E. C. Subbarao, H. S. Maiti and K. K. Srivastava // Phys. Status Solidi 21, (1974) 9.

[41] T. Mitsuhashi, M. Ichihara and U. Tatsuke // J. Am. Ceram. Soc. 57 (1974) 97.

[42] R. C. Garvie // J. Phys. Chem. 69 (1965) 1238.

[43] M. Allen, V.C. Tung and R.B. Kaner // Chem. Rev. 110 (2009) 132.

[44] S. Cranford, D. Sen and M. J. Buehler // Appl. Phys. Lett. 95 (2009) 121. 
[45] M. Yi and Z. Shen // J. Mater. Chem. A 3 (2015) 11700.

[46] D. V. Kosynkin, A.L. Higginbotham, A. Sinitskii, J.R. Lomeda, A. Dimiev, B.K. Price and J.M. Tour // Nature 458 (2009) 872.

[47] P. Miranzo, M. Belmonte and M. I. Osendi // J. Eur. Ceram. Soc. 37 (2017) 3649.

[48] S. Stankovich, D.A. Dikin, R.D. Piner, K.A. Kohlhaas, A. Kleinhammes, Y. Jia, Y. Wu, S.T. Nguyen and R.S. Ruoff // Carbon N. Y. 45 (2007) 1558.

[49] I. Y. Jeon, S. Y. Bae, J. M. Seo and J. B. Baek // Adv. Funct. Mater. 25 (2015) 6961.

[50] I.-Y. Jeon, Y.-R. Shin, G.-J. Sohn, H.-J. Choi, S.-Y. Bae, J. Mahmood, S.-M. Jung and J.M. Seo // Proc. Natl. Acad. Sci. 109 (2012) 5588.

[51] H. Zhu, Y. Cao, J. Zhang, W. Zhang, Y. Xu, J. Guo, W. Yang and J. Liu // J. Mater. Sci. 51 (2016) 3675.

[52] M. Fujita, K. Wakabayashi, K. Nakada and K. Kusakabe // J. Phys. Soc. Japan 65 (1996) 1920.

[53] M.-F. Lin and F.-L. Shyu // J. Phys. Soc. Japan 69 (2000) 3529.

[54] V. Barone, O. Hod and G. E. Scuseria // Nano Lett. 6 (2006) 2748.

[55] H. Hsu and L. E. Reichl // Phys. Rev. B 76 (2007) 045418.

[56] L. Malard, M. Pimenta, G. Dresselhaus and M. Dresselhaus // Phys. Rep. 473 (2009) 51.

[57] W. S. Hummers and R. E. Offeman // J. Am. Chem. Soc. 80 (1958) 1339.

[58] S. Pei and H. M. Cheng // Carbon N. Y. 50 (2012) 3210.

[59] M. F. García-Sánchez, J. Peña, A. Ortiz, G. Santana, J. Fandiño, M. Bizarro, F. Cruz-Gandarilla and J.C. Alonso // Solid State lonics 179 (2008) 243.

[60] O. Y. Kurapova, O. V Glumov, M. M. Pivovarov, S. N. Golubev and V. G. Konakov // Reviews on Advanced Materials Science 52 (2017) 134.

[61] J. I. Paredes, S. Villar-Rodil, A. MartiěnezAlonso and J. M. D. Tascoěn // Langmuir 24 (2008) 10560.

[62] Y. Hernandez, V. Nicolosi, M. Lotya, F.M. Blighe, Z. Sun, S. De, I.T. McGovern, B. Holland, M. Byrne, Y.K. Gun'Ko, J.J. Boland, P. Niraj, G. Duesberg, S. Krishnamurthy, R. Goodhue, J. Hutchison, V. Scardaci, A.C. Ferrari and J.N. Coleman // Nat. Nanotechnol. 3 (2008) 563.
[63] C. López-Pernía, C. Muñoz-Ferreiro, C. González-Orellana, A. Morales-Rodríguez, A. Gallardo-López and R. Poyato // Ceram. Int. 767 (2018) 994.

[64] E. B. Ramírez, A. Huanosta, J. P. Sebastian, L. Huerta, A. Ortiz and J. C. Alonso // J. Mater. Sci. 42 (2007) 901.

[65] D. Perednis and L. J. Gauckler // Solid State Ionics 166 (2004) 229.

[66] Z. A. Munir, U. Anselmi-Tamburini and M. Ohyanagi // J. Mater. Sci. 41 (2006) 763.

[67] J. Liu, H. Yan, M. J. Reece and K. Jiang // J. Eur. Ceram. Soc. 32 (2012) 4185.

[68] R. Poyato, J. Osuna, A. Morales-Rodríguez and A. Gallardo-López // Ceram. Int. 44 (2018) 14610.

[69] Z. Zeng, Y. Liu, W. Chen, X. Li, Q. Zheng, K. Li and R. Guo // J. Am. Ceram. Soc. 101 (2018) 3498.

[70] C. Ramírez, S. Vega-Diaz, A. MorelosGómez, F. Figueiredo, M. Terrones, M. Osendi, M. Belmonte and P. Miranzo // Carbon N. Y. 57 (2013) 425.

[71] H. Zou, Y. Zhang, L. Liu, L. Shi and W. Li // Adv. Appl. Ceram. 117 (2018) 420.

[72] O. Y. Kurapova, O.V. Glumov, I.V. Lomakin, S.N. Golubev, M.M. Pivovarov, J.V. Krivolapova and V.G. Konakov // Ceram. Int. 44 (2018) 15464.

[73] S. Ramesh, M.M Khan, H.C. Alexander Chee, Y.H. Wong, P. Ganesan, M.G. Kutty, U. Sutharsini, W.J. Kelvin Chew and A. Niakan // Ceram. Int. 42 (2016) 17620.

[74] K. Markandan, M. T. T. Tan, J. Chin and S. S. Lim // Ceram. Int. 41 (2015) 3518.

[75] N. Obradović and F. Kern // Ceram. Int. 44 (2018) 16931.

[76] M. Boniecki, P. Gołębiewski, W. Wesołowski, M. Woluntarski,

A. Piątkowska, M. Romaniec, P. Ciepielewski and K. Krzyżak. // Ceram. Int. 43 (2017) 10066.

[77] J. Liu, H. Guo, Y. Su, L. Wang, L. Wei, G. Yang, Y. Yang and K. Jiang // Mater. Sci. Eng. $A 688$ (2017) 70.

[78] Z. Zeng, Y. Liu, W. Chen, X. Li, Q. Zheng and K. Li, R. Guo // J. Am. Ceram. Soc. 101 (2018) 3498.

[79] S. Li, Z. Xie, Y. Zhang and Y. Zhou // Int. J. Appl. Ceram. Technol. 14 (2017).

[80] J.-W. An, D.-H. You and D.-S. Lim // Wear 255 (2003) 677. 
[81] J. Dusza, J. Morgiel, A. Duszová,

L. Kvetková, M. Nosko, P. Kun and

C. Balázsi // J. Eur. Ceram. Soc. 32 (2012) 3389.

[82] L. S. Walker, V. R. Marotto, M. A. Rafiee, N. Koratkar and E. L. Corral // ACS Nano 5 (2011) 3182.

[83] Y. Fan, L. Wang, J. Li, J. Li, S. Sun, F. Chen, L. Chen and W. Jiang // Carbon N. Y. 48 (2010) 1743.

[84] F. Chen, D. Jin, K. Tyeb, B. Wang, Y.H. Han, S. Kim, J.M. Schoenung, Q. Shen and L. Zhang // Ceram. Int. 41 (2015) 6113.

[85] B. V. M. Kumar, W.-S. Kim, S.-H. Hong, H.-T. Bae and D.-S. Lim // Materials Science and Engineering: A 527 (2010) 474.

[86] R. Cano-Crespo, B. M. Moshtaghioun, D. Gómez-García, R. Moreno and A. Domínguez-Rodríguez // J. Eur. Ceram. Soc. 38 (2018) 3994.

[87] A. Rincón, R. Moreno, A. S. A. Chinelatto, C. F. Gutierrez, M. D. Salvador and A. Borrell // Ceram. Int. 42 (2016) 1105.

[88] A. Borrell, V. G. Rocha, R. Torrecillas and A. Fernández // J. Am. Ceram. Soc. 94 (2011) 2048.

[89] V. Pantin, M. A. Valbuena, P. Esquinazi and M. E. Dávila // J. Phys. Chem. Solids 67 (2006) 546.
[90] C. Uher, R. L. Hockey and E. Ben-Jacob // Phys. Rev. B 35 (1987) 4483.

[91] L. Edman, B. Sundqvist, E. McRae and E. Litvin-Staszewska // Phys. Rev. B 57 (1998) 6227.

[92] C. Ramirez, F. M. Figueiredo, P. Miranzo, P. Poza and M. I. Osendi // Carbon N. Y. 50 (2012) 3607.

[93] B. Román-Manso, E. Domingues, F. M. Figueiredo, M. Belmonte and P. Miranzo // J. Eur. Ceram. Soc. 35 (2015) 2723.

[94] Y. Tan, H. Luo, H. Zhang and S. Peng // J. Eur. Ceram. Soc 36 (2016) 2679.

[95] S. Baskut, A. Cinar and S. Turan // J. Eur. Ceram. Soc. 37 (2017) 3759.

[96] J.-W. Sung, K.-H. Kim, and M.-C. Kang // Int. J. Precis. Eng. Manuf. Technol. 3 (2016) 247.

[97] V. S. Stubican, R. C. Hink and S. P. Ray // J. Am. Ceram. Soc. 61 (1978) 17.

[98] S. P. S. Badwal // J. Mater. Sci. 19 (1984) 1767.

[99] D. Marinha and M. Belmonte //J. Eur. Ceram. Soc. 2018 https://doi.org/10.1016/ j.jeurceramsoc.2018.09.016 (paper in press).

[100] H. Yokokawa, H. Tu, B. Iwanschitz and A. Mai // J. Power Sources 182 (2018) 400.

[101] E. V. Tsipis and V. V. Kharton // J. Solid State Electrochem. 12 (2008) 1039-1060. 